\title{
Analysis on the Optimal Model of College Physical Education under the Concept of Lifelong Sports
}

Bishu Chen

Sichuan University of Arts and Science, College of Physical Education, Dazhou 635000, Sichuan Province

Abstract: In recent years, with the rapid development of my country's economy, people have had more time to pay attention to the quality education of students, and various innovative teaching strategies that follow have effectively improved the comprehensive quality of students at all stages. Starting from the concept of lifelong physical education, this article analyzes in detail the current problems in physical education in colleges and universities, and puts forward some measures to optimize physical education in colleges and universities, hoping to provide some reference and reference for college physical education reform, and ultimately help students form a good lifelong life Sports concept.

Keywords: Lifelong Sports Concept; College Sports Teaching; Teaching Optimization; Model Exploration

Quality education focuses on guiding students to develop comprehensively in moral, intellectual, physical, aesthetic, and labor. Combined with the concept of lifelong physical education, there are many new requirements for college physical education. Teachers need to continuously reflect on the problems in traditional physical education, and carry out teaching rectification and optimization in a targeted manner, so as to help students form a lifelong physical education concept and improve their comprehensive quality. Based on many years of college physical education experience, the author analyzes the current problems in college physical education from the actual teaching situation, and proposes corresponding teaching optimization measures based on this, and aims to build a better physical learning environment for students. The reform of college physical education has laid a good foundation.

\section{Overview of lifelong sports concept}

The so-called lifelong sports refers to continuous learning and participation in physical exercises in future study and life, and can implement targeted and scientific physical exercises according to their own actual conditions, and gradually make physical exercise an important part of future life Develop a good habit of active use. This kind of educational philosophy can effectively improve the physical fitness of students and promote quality education for students. To achieve this teaching goal, teachers need to specify and standardize physical activities in physical education, and teach students to combine their physical knowledge. , According to their own actual situation, scientifically design exercise methods, allowing students to organically combine theoretical knowledge with practical activities, and promote the reform and optimization of college physical education.

\section{The problems existing in lifelong physical education in college physical education}

\subsection{Colleges and universities pay insufficient attention to physical education}

In most college teaching, colleges and universities have not strengthened the propaganda of lifelong sports theory. Although many teachers and students have a certain understanding of lifelong sports, their teaching concepts have not

Copyright (C) 2020 Bishu Chen

doi: $10.18282 /$ le.v9i7.1484

This is an open-access article distributed under the terms of the Creative Commons Attribution Non-Commercial License

(http://creativecommons.org/licenses/by-nc/4.0/), which permits unrestricted non-commercial use, distribution, and reproduction in any medium, provided the original work is properly cited. 
been integrated into actual sports teaching, and students have not mastered the correct sports. The method of exercise is just superficial to the concept of lifelong sports. In addition, most colleges and universities across the country emphasize the study of professional knowledge in the actual teaching arrangement. Under this environment, students also put most of their energy on the study of professional knowledge, and then ignore the investment in college physical education. This is also the reason why many advanced physical education concepts are difficult to implement in colleges and universities.

\subsection{The teaching methods of physical education in colleges and universities are relatively single}

Combining with previous teaching experience, traditional physical education in colleges and universities exists, teaching methods are single, teaching content is outdated, and teaching concepts are not clear. There is no fundamental difference between what students learn in college physical education courses and junior and high school physical education courses. The teaching philosophy has not been transformed. In this environment, teachers cannot accurately control the learning demands of students, nor can students learn new sports knowledge from it, and thus gradually lose interest in physical exercises, which greatly reduces the need for physical education in colleges and universities. Effectiveness.

\section{Optimized measures for college physical education under the concept of lifelong physical education}

\subsection{Update the concept of physical education and increase the importance of physical education}

The concept of lifelong physical education has obviously improved the comprehensive quality of students. If you want to cultivate the concept of lifelong physical education, you need to update the teaching concept of physical education in colleges and universities and increase the importance of physical education. First of all, teachers should abandon traditional physical education teaching methods, adhere to the teaching philosophy of taking students as the teaching soil, learn more about students' interests and hobbies, guide students to actively participate in actual teaching, and maximize their subjective initiative in learning. Secondly, teachers need to clarify the teaching goals, not just confined to the textbook itself, to extend the teaching content appropriately, highlight the importance of lifelong sports, so that students can have a more intuitive understanding of lifelong sports. Third, teachers need to build a good teacherstudent relationship with students, in order to build a better physical education environment and enhance students' enthusiasm for physical exercise.

\subsection{Improve the physical education system in colleges and universities, and cultivate students' good physical exercise habits}

Traditional physical education in colleges and universities is first restricted to class hours. Basically, there are two physical courses per week. With such a short teaching time, apart from completing specific sports projects, there is little time for students to transmit lifelong sports concepts. Therefore, colleges and universities should improve the physical education system, appropriately increase the frequency of physical education courses, and give students and teachers enough time for physical exercise, so as to cultivate students to develop good physical exercise habits and promote the spread of lifelong sports concepts.

\subsection{Guide and enhance students' interest in physical exercise}

Interest is the first driving force of learning. Physical education teachers in colleges and universities should face up to this feature, combine students' interests and hobbies in teaching activities, and set up diversified sports events to guide students to actively participate in actual teaching and Various sports competitions can be organized after class to further stimulate students' enthusiasm for exercise. For example, today's college students are very open-minded and highly individualized. Teachers can add diversified sports such as Tai Chi, hip-hop, parkour, and roller skating to physical education to meet the different sports needs of students. Students have more choices. In addition, teachers can organize some small sports competitions with students after class, or establish sports hobby clubs, integrate sports into 
students' daily life, and truly realize the educational concept of lifelong sports.

\section{Concluding remarks}

Physical education in colleges and universities is a very important part of quality education in colleges and universities. Both schools and teachers should pay attention to it, change traditional teaching concepts, incorporate new teaching methods into actual teaching, enrich the content of college physical education, and build perfect physical education. The system truly takes students as the main body of teaching and fully stimulates students' enthusiasm for sports. In addition, colleges and universities should expand the promotion of the concept of lifelong sports, encourage the organization of various offline sports competitions, build a positive and relaxed sports environment, cultivate students' awareness of lifelong sports in a subtle way, and comprehensively improve students' comprehensive quality .

\section{References}

1. Wang Yufang. Analysis of college physical education reform under the concept of lifelong physical education[J]. Sports Fashion, 2018(1):144-144.

2. Wang Shan, Yan Xiaojun. Research on college physical education under the concept of lifelong physical education [J]. World of Sports (Academic Edition), 2018, No.778(04):33+43.

3. Wang Xiaoan. Problems and development strategies of college physical education under the concept of lifelong physical education[J]. Stationery \& Sports Products \& Technology, 2018, No.409(24):168-169. 